\title{
Discovering Grade 8 Technology Teachers' Pedagogical Content Knowledge in the Tshwane District of Gauteng Province
}

\author{
Mishack T. Gumbo ${ }^{1}$ and P. John Williams ${ }^{2}$ \\ ${ }^{1}$ University of South Africa, PO Box 392, UNISA, 0003, South Africa \\ E-mail: gumbomt@unisa.ac.za \\ ${ }^{2}$ University of Waikato, Private Bag 3105, Hamilton, 3240, New Zealand \\ E-mail: pj.williams@waikato.ac.nz
}

KEYWORDS Expert Teacher. Teaching. Learning. Pedagogy. Technological Knowledge

\begin{abstract}
This paper reports on a study conducted to inquire into Grade 8 Technology teachers' pedagogical content knowledge (PCK) in the Tshwane District of the Gauteng Province of South Africa. The research question addressed was: What is Grade 8 Technology teachers' pedagogical content knowledge in the Tshwane District of the Gauteng Province? The need to address the research question was triggered by the researchers' awareness that teachers' pedagogical content knowledge is an important and under-researched area of Technology Education. PCK embodies the notion that the knowledge held by expert teachers represents a unique integration of their pedagogical techniques and their understanding of Technology subject content. To pursue this investigation, the researchers conducted interviews, observed teachers as they taught and reviewed the textbooks that the teachers used. Interestingly, the findings revealed significant diversity in the teachers' PCK - specifically in their understanding of Technology Education, the Technology Education curriculum, the pedagogy of Technology Education, assessment, resources, and indigenous technology. Finally, the researchers provide relevant recommendations.
\end{abstract}

\section{INTRODUCTION}

An important and under-researched area of Technology Education is PCK among teachers. The realisation of this gap in the body of knowledge (Williams and Lockley 2012) provided a starting point for this research which explored PCK among Grade 8 Technology teachers in the Tshwane District of the Gauteng Province of South Africa. The authors entered the study with the idea that teaching as a profession implies a need for a certain level subject expertise on the part of the teacher (Shulman 1987; Loughran et al. 2012). The content area of focus in this paper is that of Technology. The notion of the expert teacher's knowledge is commonly referred to as PCK (Ben-Peretz 2010), a concept originated and orchestrated by Shulman (1987) as being central to the teacher's knowledge. Thus, mastering the content is the basis for the relationship between the teacher and the student - this in addition to the pedagogical relationship (Kansanen 2009:6). Thus, it is assumed that helping the learner to learn means that the teacher has enough of what Kansanen refers to as curricular knowledge and pedagogical knowledge. This means that PCK goes deeper than mere teaching of the subject content in other words, the teacher possesses knowledge and skills that: distinguish him from novices or less experienced people; undergird superior reproducible performances of representative tasks; single him out as an authoritative source of knowledge, techniques and skills; and express intense experience through practice and education in a particular field (Ericsson et al. 2006; Pisova and Janik 2011). However, while emerging research has offered insights into the constitution of expert teachers, much remains to be understood still (Williams and Lockley 2012). It was for these reasons that the researchers deemed it necessary to explore the PCK of Grade 8 Technology teachers in order to determine their levels of expertise. This paper explains the theory that undergirded the study, briefly surveys the PCK literature with specific reference to Technology Education, presents and motivates the research design, presents and discusses the findings and concludes by making a number of necessary recommendations.

\section{Theoretical Framework}

This study is premised on the seminal work of Shulman (1987) on PCK. PCK refers to the body of the teacher's professional knowledge that encapsulates the knowledge of the subject taught and the general pedagogical principles and skills (Ben-Peretz 2010; Moru and Qhobela 2013). The ideals of this knowledge are to transform subject matter knowledge to facilitate learn- 
er understanding (Shulman 1986). Shulman (1987) developed a seven-part classification on which teacher knowledge is based, namely; subject matter, pedagogical content, general pedagogy, curriculum, learners and their characteristics, educational contexts and educational aims, and purposes and values. Shulman (1986) noted a lack of research having been undertaken into PCK, referring to it as a "missing paradigm". Prompted by this, and given the relative newness of Technology Education in the schools curriculum, the authors felt that there was an urgent need to investigate PCK among Technology teachers.

It is noted that, in the period since 1986, Shulman's work on PCK has attracted many scholarly reactions. For example, Segall (2004) questioned Shulman's shallow treatment of the interaction between pedagogy and content. Cochran et al. (1991) focused on only four aspects of the seven-part elements of the PCK, namely; the subject matter, the learners, environmental contexts and pedagogy. Magnusson et al. (1999), meanwhile, proposed five elements instead of seven, which include orientations towards teaching, knowledge of curriculum, knowledge of assessment, knowledge of students' understanding of the subject, and knowledge of instructional strategies. This paper, then, is intended to shed some light on how teachers treat the relationship between pedagogy and content in their teaching of technology as a school subject.

Another dimension to PCK was captured in Ben-Peretz's (2010) study in which he wrote that teachers construct their own meaning about their own teaching. This meaning is informed by a repertoire of factors such as the context of teaching and learning, subject-specific pedagogies and knowledge of learners (Ben-Peretz 2010; Loughran et al. 2012). Ben-Peretz conducted a study on teacher knowledge. She analysed nine papers published in Teaching and Teacher Education between 1988 and 2009. The papers were authored by scholars from different contexts. They reflected modes of inquiry and focused on a variety of themes related to teacher knowledge. Her analysis was done according to the definition of teacher knowledge, mode of inquiry, emphasis on one or more common places of education, and emphasis on one or more kinds of teacher knowledge. The findings revealed that the elements comprising teacher knowledge were in line with Shulman's elements. From Ben-
Peretz's findings, the definition of teacher knowledge was expanded to include global issues and multiculturalism. In the research undertaken for this paper the researchers focused on Technology teachers' understanding of Technology Education as well as their knowledge of curriculum, pedagogical strategies, integration of resources, assessment strategies and indigenous technology. The inclusion of indigenous technology as part of the explored PCK is justified in the following section. The researchers approached the study with the knowledge that teachers' PCK develops over time through experience (Loughran et al. 2012; Williams and Lockley 2012), and that PCK differs among teachers, even within the same subject area (though a certain degree of similarity cannot be ruled out). This is because PCK is a particular expertise with individual idiosyncrasies and differences (Loughran et al. 2012; Makina 2013). The PCK of the four teachers studied was thus approached as case studies that potentially exhibited some degree of differences as a result of the factors expressed above. The next section looks closely at PCK as it pertains to Technology Education.

\section{PCKAs It Pertains To Technology Education}

The authors deemed it necessary to approach this section by briefly relating developments in Technology Education as part of curriculum change and implementation in South Africa. Since its inception in 1998, the national curriculum for Grade R - 9 has undergone a number of reviews (Department of Education 2000). The first was Curriculum 2005, followed by the National Curriculum Statement, then the Curriculum and Assessment Policy Statement (CAPS). According to CAPS (Department of Basic Education 2009), the aims of Technology as a subject require learners to:

- develop and apply specific design skills to solve technological problems;

- understand the concepts and knowledge used in Technology Education and use them responsibly and purposefully; and

- appreciate the interaction between peoples' values and attitudes, technology, society and the environment.

These curriculum reviews have implications for the PCK of Technology teachers and their conceptualisation of what being a successful 
Technology teacher means (Nicholas and Lockley 2010). The Department of Basic Education is committed to promoting indigenous technology as part of curriculum transformation (Gumbo 2012). For this reason, indigenous knowledge systems are part of the curriculum principles. For Technology education specifically, the third aim above includes indigenous technology, explicitly expressed in CAPS (Department of Basic Education 2009). The researchers therefore included this aspect in their investigation in order to develop an idea as to how Technology teachers incorporate it as part of their own PCK.

Rohaan et al. (2009) posit that it is of great importance that teachers have sufficient knowledge of Technology to develop learners' technological literacy. In the context of PCK, Technology teachers should acquire a thorough knowledge of content and pedagogy in order to be effective in their teaching. Jones and Moreland (2004:124) assert that teachers cannot provide experiences and activities that guide student progress towards understanding ideas if they themselves do not know what the ideas are. Technology teacher knowledge is about what Technology is; its philosophy and its thematic domains, and how to teach it to learners. Technology is "the human activity that transforms the natural environment to make it fit better with human needs, thereby using various kinds of information and knowledge, various kind of natural (materials, energy) and cultural resources (money, social relationships, etc.)" (de Vries 2005: 11). Technology involves the use of knowledge, skills and resources with the aim of meeting people's needs and wants by developing practical solutions to problems whilst also taking into account social and environmental factors (Department of Basic Education 2009). According to de Vries (2005: 8), the philosophy of Technology Education can be an inspiration for determining the content of curriculum. It can yield insights into how to construct teaching and learning situations, can provide a conceptual basis and proper understanding of Technology (which can help Technology teachers respond to unforeseen situations while teaching about Technology), can help position the teaching of Technology among other subjects, and can help identify research agenda for educational research in Technology Education.

Jones and Moreland (2005) suggest that teachers require a clear understanding of the nature of Technology and the conceptual and procedural aspects of the different technological areas. This content consists of conceptual knowledge of Technology as an artefact and procedural knowledge on the design and make of these artefacts. It is the possession of conceptual knowledge that makes the effective use of procedural knowledge of problem solving possible (Glaser in McCormick 2004: 149). Within conceptual knowledge are the themes of Technology such as Structures, Systems and Control, Materials and Processing, and Communication. "Knowledge, skills, and attitudes needed to solve technological problems can be sourced from other learning areas such as Science, Mathematics, Arts and Culture, etc.” (Engelbrecht et al. 2007: 586-589).

Teachers should facilitate the technological process so that learners can practise the procedural knowledge. The technological process is about identifying a problem, investigating possible solutions to the problem, designing a suitable solution to the problem, producing the designed solution and then evaluating the solution while focusing on the different themes of Technology within different contexts (Mawson 2007: 119). The teaching of Technology happens through identifying and solving technological problems and, for this to happen, the technological process plays a key role in directing the problem-solving activities.

\section{RESEARCH DESIGN AND METHODOLOGY}

The study followed a case study design to investigate Grade 8 Technology teachers' PCK (Neale et al. 2006) in an attempt to answer the research question: What is Grade 8 Technology teachers' pedagogical content knowledge in the Tshwane District of the Gauteng Province? The PCK-related questions that emanated from this main research question and which were used to gather data are stated as follows:

- How do teachers express their PCK in terms of their understanding of the nature and purpose of Technology Education?

- How do teachers express their PCK in terms of their knowledge of the Technology Education curriculum?

- How do teachers express their PCK in terms of pedagogies that they consider suitable for Technology teaching? 
- How do teachers express their PCK in terms of types of assessment activities and how do they relate them to the Technology content?

- How do teachers express their PCK in terms of teaching and learning resources for Technology teaching?

- How do teachers express their PCK in terms of integrating indigenous technology in their teaching?

The study targeted Grade 8 Technology teachers in the Tshwane District of the Gauteng Province. Four Grade 8 Technology teachers from four schools were conveniently selected two were based in city schools, one in a township school and one in a rural school. In one school there was only one teacher who was responsible for the Grade 8 class. In all cases participants were identified as "expert" teachers and were willing to cooperate. Permission to conduct the study was sought from and granted by the Gauteng Provincial Department of Education. Access to the schools was sought by first visiting each school to deliver letters of consent and to have them signed by the respective school principals and the teachers to be sampled. To allow for the teachers to be observed presenting classes, a letter of consent was sent with the help of the teachers to the affected parents for their signatures.

The researchers negotiated a convenient day to observe and interview the teachers. They used an observation sheet to note the PCK elements that were demonstrated during teaching. The researchers co-observed each teacher's teaching in order to counter the possibility of bias (Kelly 2006). Once the observations had been conducted, the researchers integrated the data on a final observation sheet. Observation was followed by interviews with the teachers in order to explore their perspectives on PCK. A document review focused on the textbooks in use to understand how they were integrated and articulated during the teaching activities. To ensure the validity of the interview data, the interviewees were asked to confirm what they had said once the data had been transcribed. The findings from the interviews, observations and document reviews were triangulated to ensure validity of the data.

Regarding data analysis, the researchers adopted a variation of Marshall and Rossman's (1999) coding strategy which involves a step- wise process. This process moves from a general approach of listening to the recordings, to developing themes and codes, to noting the themes from the transcribed data, and then detailing the themes. The coding strategy followed analyst-constructed typologies based on the principles of PCK developed from the literature. The analyst-constructed themes included teacher understanding of Technology Education, of the Technology Education curriculum, of pedagogy, of assessment, of resources and of integration of indigenous technology. The interview questions and the reporting of the findings were based on these themes. Once the audio transcripts had been analysed, they were integrated with the teaching observation notes and document reviews. The outcome was the presentations of the findings with pseudonyms substituted for teacher's names in order to protect their identities.

\section{FINDINGS}

Findings from different sources of data (interviews, observation and document analysis) are presented. Initially, each of the four cases is briefly contextualised (Table 1), noting some features of the observations that were made. This is followed by the presentation of findings under six research questions. Pseudonyms were assigned to the teachers to protect their identity. It should be noted that all the schools were co-educational.

The integrated findings of these cases will now be presented in order to find answers to the research questions asked.

How Did Teachers Express Their PCK In Terms of Their Understanding of the Nature and Purpose of Technology Education?

Context impacts on the nature of teachers' PCK as it relates to their understanding of Technology Education. In general terms, all four teachers realised the importance of relating Technology Education to an authentic context, an important element of PCK which helps make the teaching of Technology meaningful to learners. Their conception of Technology is that it is applicable in people's daily lives and that it thus cannot be divorced from the authentic context in response to people's needs. The teaching approach has to be contextualised. Lerato, one of the "expert" teachers alluded to this claim in the following manner: 
Table 1: The contexts of the four schools presented through the teachers sampled

Moropa (Male)
Biographical
Moropa is 47 years old and has been teaching for 13
years (seven of which have been in teaching
Technology). Moropa started as a science teacher. He
holds a BA, BEd (Hons) and an ACE: Technology
Education.
Context and Teaching
School and Learners: Moropa teaches in a rural school
which has 830 learners. There were 30 learners in his
classroom in groups of four each.
Classroom: The classroom was bare - there was a
chalkboard only and there no technological tools/
materials or storage room. The computer room was
used for storage. Learners were asked to bring their
own materials from home for their design projects.
Lesson and Activity: Design portfolio templates were
handed out to learners. There were also box design
projects (individual/group). In addition. there were
templates with sketch spaces for design and idea
development, and questions to consider during design.

Lerato (Female)

\section{Biographical}

Lerato is 25 years old and has been teaching Technology for the past four years. She has a BEd degree.

\section{Context and Teaching}

School and Learners: Lerato teaches in an urban school which has 100 learners.

Classroom: There were two woodwork benches at the rear of the room. There was a storeroom which was part of the classroom with some tools and equipment. There was a nice display of previous projects on the benches at the front of the room. These projects included a suspension bridge, examples of water towers and house artefacts.

Lesson and Activity: There was a water tower group design project coupled with work on processing and the properties of materials. There was built-in peer assessment and there was heavy use of a textbook that learners were constantly referred to.

\section{Biographical}

Ms Mapula is 39 years and has been teaching for seven years, four of which have been in teaching Technology. She has a diploma in Maths and Science Education, and an ACE in Education Management. Ms Mapula volunteered to teach technology.

\section{Context and Teaching}

School and Learners: Mapula teaches in an urban school with at least 1158 learners. There were five groups of eight learners and a total of 40 learners in her class.

Classroom: There were no Technology tools/materials or storage facilities and only a chalkboard was present. There were, however, a few old posters on the wall. The teacher would constantly ask the learners to bring along design project materials from home.

Lesson and Activity: There was a food design project and the learners were divided into groups. On the day of observation there was only one group which was prepared. There was time for questions and answers and all the answers were written on the chalkboard. The teacher awarded marks for presentations. Learners in the classroom seemed very interested because what was done drew much from real life examples.

$$
\text { James (Male) }
$$

\section{Biographical}

James is 30 years old and has been teaching Technology for four years. He holds a BEd Technology Education. James comes from an engineering and graphic design background.

\section{Context and Teaching}

School and Learners: James teaches at an urban school with 1300 learners. There are 35 learners in his class seated at long benches. Classroom: The learners' folders were kept in drawers. The Technology tool kit was locked away. There were models, teaching aids in the classroom and posters on the wall.

Lesson and Activity: The structures were textbookbound, teacher-centred and backed by case studies and demonstrations. Lessons were conducted using the question and answer method by referring learners to the textbook most of the time.
You cannot make before you know that there is a need for that particular product for a particular market.

The authentic aspect of Technology is aligned to the national needs. James and Lerato, as Technology teachers, recognised the need for skills development which is strongly espoused by government. Future architects, engineers and business people need to play a meaningful role in filling the gap and in minimising foreign dependency. James stated in this regard:

It will help learners learn about Technology so that they can add to the skills develop- ment in the country. We depend on people from other countries rather than those from our country for most of these scarce-skills careers. Technology Education will help minimise this.

Some teachers considered the importance of facilitating the learners' understanding of Technology Education. In particular, Mapula and Moropa stated:

Technology is fine because it teaches learners about things that they were ignorant about before. Like now we have been doing a structures project, suspension bridge and learners do not know structures. I even told them to go 
to places like Johannesburg to see some of the structures like Mandela Bridge [Mapula].

Technology is very important for learners. If they can be interested in learning Technology, then they can use ATM, cellphone, internet and computer better [Moropa].

Moropa stated that he preferred teaching Technology to science because learners were more interested in studying Technology than science. It seemed that this teacher did not understand the interdisciplinary nature of the PCK of Technology and Science because he sounded as if he had completely abandoned Science in favour of Technology instead of taking advantage of the synergy between the two study areas. Unlike Moropa, Mapula demonstrated a good sense of this interdisciplinary aspect:

Technology is linked with physical Science. Like in the one of the chapters we are doing systems and control. It includes electricity which is also part of Physical Science. Learners must know properties of materials and what these materials are used for.

These teachers were also aware of the design process (investigate, design, make, evaluate and communicate). This indicated their awareness of the curriculum requirements as an element of PCK. For these teachers, the underlying purpose of teaching learners Technology is to equip them with the design knowledge and skills to prepare them to make a functional fit in the technological environment in which they will work in future. James, however, argued that there is more to Technology than simply the design process:

The focus on design is not enough. When you look at any company in the world, what goes into the design of a cup in industry, for example, you will realise that there is more to it than the design process only. Yes, the learners will in the end know more about design, but there is more knowledge around it.

How Did Teachers Express Their PCK In Terms of Their Knowledge Of The Technology Education Curriculum?

Teachers were aware of the curriculum and what was expected from them in this regard. However, their knowledge of the basic elements of curriculum and principles varied. This could be attributed to the curriculum reviews presenting different understandings to teachers. Another possibility might have to do with contex- tual differences. Because of these differences teachers could conceptualise the PCK of the curriculum in their own ways. Moropa articulated the learning outcomes [referred to as aims in CAPS] and how he envisaged their achievement:

Technology has three learning outcomes. Today we dealt with the knowledge learning outcome which is outcome number two - because the learners had to know the characteristics of materials for the project that they will do later. I was giving them the knowledge foundation.

James felt strongly about anchoring learners in the required technological knowledge. Thus, he emphasised knowledge outcome/aim two, even though he was aware of outcomes/ aims one and three. He was also aware of the emphasis placed by the curriculum policy on continuous assessment which targets learners' knowledge, skills and attitude. It was evident during the observation that he integrated assessment with his teaching.

Mapula and Lerato did not have a clear understanding of the curriculum. Mapula vaguely referred to the learning outcomes, while Lerato mixed them up:

Learning outcome one is about structures, learning outcome two is about processing and learning outcome three is about systems and control.

How Did Teachers Express Their PCK in Terms Of Pedagogies That They Considered Suitable for Technology Teaching?

The teachers' responses to this question varied from the pedagogical strategies to how they involved their learners. Moropa preferred to do concept clarification first before engaging learners in any design activities. Lerato's pedagogies were about doing diagnostic assessment of the learners prior to developing their knowledge of Technology: "We move from the known to the unknown". She then involved them actively in the learning activities:

When you do Technology practically, they remember but when you simply do theory with them, they easily forget.

James seemed to have a good understanding of his learners as he claimed that they were lacking in critical thinking skills and that it was his aim to encourage the development of their technological knowledge. James seemed to be primarily concerned about learner understanding, an important aspect of PCK. 
How Did Teachers Express Their PCK in Terms of Types of Assessment Activities and How Did They Relate Them to the Technology Content?

The teachers considered a range of assessment strategies and methods and how they could be implemented. The strategies of assessment included weekly tests, end-of-term examinations, a design project portfolio, case studies, homework, and classwork. Types of assessment included teacher assessment, self-assessment, peer assessment and group assessment. Teachers commonly base their assessment strategies on design project portfolios. Group-based design project assessment was favoured by some teachers but not by others. Lerato favoured it and she explained how she implemented and managed it:

They also have to produce a project that I must assess. I assess them on the design process and technological processes. The design project portfolio contains individual activities and group activities and they are assessed as such. Individual activities go up to the design stage where each group member must design at least three possible solutions, evaluate them on the basis of advantages and disadvantages of each, and choose the optimum solution. Then the members must negotiate the optimum solution from each member's best one, to adopt as a group design. Group members assign each other time frames specifying when to complete the project within the main assigned time frame.

Lerato explained that she always provided a rubric together with the design project so that the learners would know how their project would be assessed. Mapula was uncomfortable with the group-based design project assessment as she claimed that it encouraged certain group members to shirk their responsibilities. James had a fixed plan for writing tests:

On Tuesdays and Thursdays we have 30 minute tests. Learners are expected to diarise them.

It can be concluded that, though teachers use a variety of assessment activities, the predominant assessment activity is the design project with its associated portfolio.

How Did Teachers Express Their PCK In Terms of Teaching and Learning Resources for Technology Teaching?

Instructional strategies as an element of PCK imply that there will be resources for the instruction given. The teachers commonly made exten- sive use of textbooks. The schools involved had learner-teacher support material teams who attended exhibitions for the purpose of selecting textbooks. The researchers were made aware of a variety of textbooks that the teachers had chosen for their schools, for example, Dynamic Technology (Clitheroe et al. 2005) and Spot-on Technology 8 (Holdt and Richter 2006). The teachers' views illustrate the polarisation between wellresourced schools (James' and Lerato's) and poorly resourced (Moropa's and Mapula's) schools. Moropa asked learners to bring basic materials from home from which to produce prototypes. He and Mapula felt that Technology Education was not being taken seriously because it was not being adequately supported by the Department of Basic Education or by the schools. Mapula had this to say in this regard:

We do not have resources. I have provided the school with the list of items that we need for Technology teaching. I have not received anything yet. There is a lot that we need to be able to teach a topic, like structures. We have to find a workshop for Food Technology, Systems and Control, and the like; we do not have any.

Lerato listed, among other things, glue guns, bulbs, electric circuits, screwdrivers, sandpaper and money clips. James used his laptop computer and data projector because how can one be a Technology teacher without a computer? Though he used the textbook a great deal, he thought that working from the laptop is a lot better. He used an overhead projector and transparencies for his Engineering Design Drawing subject. The setup in his Technology Education classroom included plugs under the learners' tables to allow them to plug in power tools.

How Did Teachers Express Their PCK In Terms of Integrating Indigenous Technology in Their Teaching?

There was evidence of indigenous technology integration on a small scale. Teachers were guided to some extent by certain chapters in the textbooks which integrated indigenous technology. Lerato used such chapters as a springboard to let learners express their technological understanding. The learners' indigenous cultural backgrounds were expressed in this regard. For example, Lerato explained as follows:

Last year when we did processing, learners had a bead project. Some learners' colour choice for the beads had to do with beads for healing. 
Moropa planned to integrate indigenous technology into the packaging project: We will talk about packaging by the Bushmen who used to carry water in eggshells.

James and Mapula appeared surprised to hear the term "indigenous technology" as they had not thought about integrating it prior to the interviews. James explained his position in this regard:

The textbook does integrate indigenous technology. We touched a little on it in chapter two. But I must be truthful to say we have not done much yet to integrate it. Our limitation seems to lie in the fact that we seem to take from foreign curriculum. In my class are children from Akasia and beyond; coloureds, Zulus and Xhosas. Some come from indigenous contexts. So, we need to integrate their indigenous contexts in the curriculum.

Mapula stated that she did not remember ever having integrated indigenous technology in her teaching.

\section{DISCUSSION}

The findings yielded some interesting teacher perspectives that could be linked to contextual differences as reflected in Table 1 . The teachers' technological PCK in as far as their understanding of Technology Education was commonly related to societal context. This expressed understanding seems to be in line with de Vries' (2005: 11) definition of Technology: a "human activity that transforms the natural environment to make it fit better with human needs, thereby using various kinds of information and knowledge, various kind of natural and cultural resources". The teachers expressed the practical nature of Technology education - and thus the need for teaching Technology with the aim of producing future technologists able to contribute to the development of the country. They seemed to possess a reasonable understanding of Technology Education and what and how they planned to teach their learners. According to Rohaan et al. (2009), teachers should possess technological knowledge in order to facilitate learners' technological literacy. The teachers in this study expressed varied understanding of the curriculum. Their focus was more on the learning outcomes/aims which are encapsulated in the curriculum document (Department of Basic Education 2009). Only one teacher, however, seemed to know these learning outcomes/ aims as he mentioned that: Technology has three learning outcomes. Today we dealt with the knowledge learning outcome two because the learners had to know the characteristics of materials for the project that they will do later. I was giving them the knowledge foundation.

In as far as pedagogical approaches are concerned the teachers exhibited different approaches to their teaching - these were expressed in terms of concept clarification, starting with the known to the unknown, and so on. However, what was common to their different approaches is that they focused on the learner, making efforts to facilitate understanding of the content. Their assessment of learners was informed by varied approaches according to their personal preferences. The predominant approach, however, was the design project approach. It seems that the teachers' PCK was prescriptive in this regard because design is emphasised in the curriculum as it is part of learning outcome/aim one (Department of Basic Education 2009). Resources, which are crucial in helping teachers express their technological PCK as they teach learners, were not readily available. This state of affairs frustrated the teachers to a great extent. They blamed the undersupply of resources on the Department of Basic Education and schools. As a result, they relied mainly on textbooks - Dynamic Technology (Clitheroe et al. 2005) and Spot-on Technology 8 (Holdt and Richter 2006). These resources included minimal sections or chapters on indigenous technology. However, teachers did not take full advantage of this or give regard to the fact that the third learning outcome/aim includes indigenous technology (Department of Basic Education 2009).

This study was faced by certain limitations. The study did not target common Technology themes. To do so would have been impractical as the teachers themselves were engaged with differing themes at the time of the study. Context played a role in the study in terms of how the different natures of the teachers' PCKs were revealed. Hence, the researchers cannot conclude that the teachers' PCK is similar across contexts, although the study does provide an insight into the teachers' PCK.

\section{CONCLUSION}

In this paper the surveyed literature on PCK revealed the dynamic conceptualisation of PCK 
and how teachers implement this concept in their practice. Four Grade 8 Technology teachers were interviewed and observed in class, and the research ended with document analysis conducted with the intention of revealing these teachers' PCK. There were certain similarities and divergences in the four teachers' PCKs in these case studies. This suggests that PCK is individual, unique, varies from class to class and changes over time. Regarding the similarities, almost all of the teachers were aware of the impact of the subject context on Technology Education and they were also aware of the value of teaching Technology to learners in view of their future careers and the development of the country in general. All the teachers stated that they were guided by the curriculum and that they knew what was expected of them. Teachers also conceded that they depended heavily on the prescribed textbook. The divergences between the teachers seemed bigger than the similarities, though. Teachers differed in their understanding of the concept of Technology. While on the one hand some teachers recognised Technology's complementary nature to science and vice versa, on the other hand, other teachers viewed the two subjects as two entirely different entities. While all the teachers were aware of the weight accorded to the design process (technological process) regarding the teaching of Technology, they held differing views about it and its use. They also approached the learning outcomes (aims) differently, and placed varying emphasis on them. Disappointingly, some teachers were not really sure of their knowledge of the learning outcomes. They also differed sharply in their pedagogical strategies, varying in terms of emphasis on concept clarification and diagnostic assessment and the like. Understandably, assessment strategies varied greatly between types of assessments and projects. Some teachers attempted to embed indigenous technology although they had a limited understanding of it, whereas others did not integrate it at all. As a framework for developing an understanding of teachers' PCK, the methodology used seems to have been appropriate. The observation of teacher context and teaching, the interview, and to a lesser extent document analysis, together proved to be a rich data source. The data was generally triangulated in order to provide valid results. In those instances in which triangulation did not validate data, for example where teachers' interviews did not match the observations of their classes, dual sources of data become particularly important. Although all the participating teachers in this project were teaching the same year span of students and following the same curriculum, diverse PCK was revealed, even though there were interesting commonalities in a few notable instances.

\section{RECOMMENDATIONS}

Bearing in mind the findings, the researchers would seriously advise Technology teachers to take the initiative in building their own PCK by reading up on the necessary elements and making sure that they know and clearly understand the Technology Education curriculum. It is therefore recommended that Department of Basic Education and relevant higher education institutions offer specialised training to Technology teachers, especially in view of the fact that Technology Education is a relative newcomer in the curriculum. For instance, training on structures should last for a quarter at least in order to allow teachers to be sufficiently exposed to learning about and teaching this theme. This would allow them to proceed with much added confidence. We believe that future studies should consider targeting common themes that teachers deal with in the field of Technology. In saying this, we are fully aware that there could be practical challenges in doing so due to tight school scheduling.

\section{REFERENCES}

Ben-Peretz M 2010. Teacher Knowledge: What Is It? How Do We Uncover It? What Are Its Implications For Schooling? From <http://dx.doi.org/10.1016/ j.tate.2010.07.015> (Retrieved on 17 August 2011).

Clitheroe F, Dilley L, Tholo T 2005. Dynamic Technology. Cape Town: Kagiso.

Cochran KF, King RA, DeRuiter JA 1991. Pedagogical Content Knowledge: A Tentative Model for Teacher Preparation. East Lansing, MI: National Centre for Research on Teacher Learning.

De Vries MJ 2005. An Introduction to the Philosophy of Technology for Non-philosophers. Dordrecht: Springer.

Department of Education 2000. South African Curriculum for the Twenty-first century: Report of the Review Committee on Curriculum 2005. Pretoria: Government Printers.

Department of Basic Education 2009. Curriculum and Assessment Policy Statement (CAPS) Technology Grades 7-9. Final Draft. Pretoria: Government Printers. 
Engelbrecht W, Ankiewicz P, De Swardt E 2007. An industry-sponsored, school-focused model for continuing professional development of technology teachers. South African Journal of Education, 27(4): 579-595.

Ericsson KA, Charness N, Feltovich PJ, Hoffman RR 2006. The Cambridge Handbook of Expertise and Expert Performance. Cambridge: Cambridge University Press.

Gumbo MT 2012. Claiming indigeneity through the school curriculum, with specific reference to technology education. Africa Education Review, 9(3): 434-451.

Holdt JMD, Richter EFS 2006. Spot-on Technology 8. Sandton: Heinemann.

Jones A, Moreland J 2004. Enhancing practicing primary school teachers' pedagogical content knowledge in technology. International Journal of Technology and Design Education, 14(2): 121-140.

Jones A, Moreland J 2005. The importance of pedagogical content knowledge in assessment for learning practices: A case-study of a whole-school approach. The Curriculum Journal, 16(2): 193-206.

Loughran J, Berry A, Mulhall P 2012. Understanding and Developing Science Teachers' Pedagogical Content Knowledge. $2^{\text {nd }}$ Edition. Rotterdam: Sense.

Kansanen P 2009. The curious affair of pedagogical content knowledge. Orbis Scholae, 3(2): 5-18.

Kelly P 2006. Observation Techniques. Plymouth: University of Plymouth.

Magnusson S, Krajcik J, Borko H 1999. Nature, sources, and development of pedagogical content knowledge for science teaching. In: J Gess-Newsome, NG Lederman (Eds.): Examining Pedagogical Content Knowledge: The Construct and its Implications for Science Education. Dordrecht, The Netherlands: Kluwer Academic, pp. 95-132.

Makina A 2013. Designing a PCK Framework for the Professional Development of Statistics Teachers. A Paper Presented at $21^{\text {st }}$ Meeting of the Southern African Research Mathematics, Science and Technology Education, Cape Town, 15 January 2013.
Marshall C, Rossman GB 1999. Designing Qualitative Research. $3^{\text {rd }}$ Edition. Thousand Oaks: Sage.

Mawson B 2007. Factors affecting learning in technology in the early years at school. International Journal of Technology and Design Education, 17(3): 253-269.

McCormick R 2004. Issues of learning and knowledge in technology education. International Journal of Technology and Design Education, 14(1): 21-44.

Moru K, Qhobela M 2013. Secondary school teachers' pedagogical content knowledge of some common student errors and misconceptions in sets. African Journal of Research in Mathematics, Science and Technology Education, 17(3): 230.

Neale P, Thapa S, Boyce C 2006. Preparing a Case Study: A Guide for Designing and Conducting a Case Study for Evaluation Input. From <www.pathfind.org/ site/DocServer/m_e_tool_series_case_study.pdf $>$ (Retrieved on 04 October 2011).

Nicholas M, Lockely J 2010. The Nature of Technology: Teachers' Understanding of Design and Knowledge in Empowering Technological Practice in Education. From <www.tenz.org.nz/2009.papers-pdf> (Retrieved on 21 June 2010).

Pisova M, Janik T 2011. On the nature of expert teacher knowledge. Orbis Scholae, 5(2): 95-115.

Rohaan EJ, Taconis R, Jochems WMG 2009. Measuring teachers' pedagogical content knowledge in primary technology education. Research in Science and Technological Education, 27(3): 327-338.

Segall A 2004. Revisiting pedagogical content knowledge: The pedagogy of content/the content of pedagogy. Teaching and Teacher Education, 20(5): 489504.

Shulman LS 1986. Those who understand: A conception of teacher knowledge. American Educator, 10: 9-15.

Shulman LS 1987. Knowledge and teaching: Foundations of the new reform. Harvard Educational Review, 57(1): 1-21.

Williams PJ, Lockley J 2012. An Analysis of PCK to Elaborate the Difference between Scientific and Technological Knowledge. A Paper Presented at PATT26 Conference. Stockholm, June 272012. 